\title{
A Self-Healing Ionic Liquid-Based Ionically Cross-Linked Gel Polymer Electrolyte for Electrochromic Devices
}

\author{
Wanyu Chen ${ }^{1}$, Siyuan Liu ${ }^{1}$, Le Guo ${ }^{2}$, Guixia Zhang ${ }^{1}$, Heng Zhang ${ }^{1}$, Meng Cao ${ }^{1}$, Lili Wu ${ }^{1}$, Tianxing Xiang ${ }^{2}$ \\ and Yong Peng $2, *$ (D) \\ 1 School of Materials Science and Engineering, Wuhan University of Technology, Wuhan 430070, China; \\ chenwanyu@whut.edu.cn (W.C.); liusiyuan_YSL@whut.edu.cn (S.L.); zhang94670@whut.edu.cn (G.Z.); \\ zhang-hg@whut.edu.cn (H.Z.); caomeng19970705@163.com (M.C.); polymer_wl@whut.edu.cn (L.W.) \\ 2 State Key Laboratory of Advanced Technology for Materials Synthesis and Processing, Wuhan University of \\ Technology, Wuhan 430070, China; catchyue@gmail.com (L.G.); xiangtianxing@whut.edu.cn (T.X.) \\ * Correspondence: yongpeng@whut.edu.cn
}

Citation: Chen, W.; Liu, S.; Guo, L.; Zhang, G.; Zhang, H.; Cao, M.; Wu, L.; Xiang, T.; Peng, Y. A Self-Healing Ionic Liquid-Based Ionically Cross-Linked Gel Polymer Electrolyte for Electrochromic Devices. Polymers 2021, 13, 742. https://doi.org/ $10.3390 /$ polym 13050742

Academic Editor: Jui-Ming Yeh

Received: 8 February 2021

Accepted: 23 February 2021

Published: 27 February 2021

Publisher's Note: MDPI stays neutra with regard to jurisdictional claims in published maps and institutional affiliations.

Copyright: (C) 2021 by the authors. Licensee MDPI, Basel, Switzerland. This article is an open access article distributed under the terms and conditions of the Creative Commons Attribution (CC BY) license (https:/ / creativecommons.org/licenses/by/ $4.0 /)$.

\begin{abstract}
An ionic liquid-based ionically cross-linked gel polymer electrolyte (GPE-ILs) was successfully synthesized using acrylic acid, 2-diethylaminoethyl methacrylate, methyl methacrylate, and ionic liquids. Electrochromic devices (ECDs) with an architecture of glass $/ \mathrm{FTO} / \mathrm{WO}_{3} / \mathrm{GPE}-$ ILs/FTO/glass were fabricated by a laminating technology. The devices showed performances of large optical modulation of $49.9 \%$ at $650 \mathrm{~nm}$, short switching times with the coloration time (tc) of $7 \mathrm{~s}$ and the bleaching time (tb) of $4 \mathrm{~s}$, high coloration efficiency of $96.2 \mathrm{~cm}^{2} \mathrm{C}^{-1}$, and cycling stability of 200 cycles. The GPE-ILs exhibits high ionic conductivity, superior thermal stability and good self-healing ability. GPE-ILs demonstrates an ionic conductivity of $3.19 \times 10^{-3} \mathrm{~S} \mathrm{~cm}^{-1}$ at $25^{\circ} \mathrm{C}$ and the same ions migration behaviors with most widely used liquid electrolyte between -10 and $80{ }^{\circ} \mathrm{C}$ maintains more than $80 \%$ of its tensile strength after self-healing and received only $5 \%$ weight loss at $300{ }^{\circ} \mathrm{C}$.
\end{abstract}

Keywords: electrochromic device; ionically cross-linked gel; electrolyte; ionic liquids

\section{Introduction}

Electrochromic devices (ECDs) have attracted extensive attentions in last decades because of their applications in energy saving technologies, like smart windows, low-power displays, electronic skins, etc. [1-4]. However, most ECDs are suffering stability and safety problems even they have advantages of low power consumption, high color rendering efficiency, short switching time, etc. [5-8].

In a typical ECD device, electrolytes with high ionic conductivity, high transparency, good thermal stability, and good electrochemical stability were desired [9-12]. Liquid electrolytes and solid electrolytes are popular, nevertheless, liquid electrolytes are encountering volatilization and leakage $[13,14]$ and solid electrolytes are suffering from low response time and non-uniform coloring $[15,16]$. Gel polymer electrolytes (GPEs) were considered as one of the ideal electrolyte candidates because of good mechanical properties of molding ability (e.g., character of self-healing) [17-19] but ion conductivity at subzero temperatures and fatigue properties need a further improvement before considering real applications [20,21].

Non-covalent bonds (physically cross-linked) and dynamic covalent bonds (chemically cross-linked) are strategies of synthesizing self-healing gels [22], self-healing materials can heal themselves after suffering external mechanical damage or harsh environments, thereby effectively extending the service life of the material and improving its safety [23]. Generally, non-covalent bonds such as hydrogen bonding, hydrophobic bonding, and electrostatic attraction can be used as the driving force for the self-healing of materials [24-26]. The ionically cross-linked polymer network is combined by the electrostatic attraction of 
high density between negatively and positively charged groups on polymer chains [27,28]. When the ionically cross-linked polymer network is destroyed, due to the movement, rearrangement, and electrostatic attraction of the polymer chains, the network reconnects to form ionic bonds that promote the self-healing of the damaged area [22]. Ionic liquids (ILs) have many excellent properties, such as low vapor pressure, nonflammability, high thermal stability, high ionic conductivity, and wide electrochemical window [29-32]. GPEs will receive an improved ionic conductivity and long-term stability if ILs were introduced, e.g., Fernandes et al. used sol-gel method to prepare an organic-inorganic hybrid material containing ionic liquids as an electrolyte in ECD [33,34]. Studies about ILs-based chemically cross-linked GPEs have been commenced [35-38] but only a few researchers synthesized transparent ionically cross-linked GPEs because of compatibility between ILs and ionically cross-linked networks. For applications of ECDs, a transparent GPE was expected. Therefore, in order to obtain ILs-based ionically cross-linked GPEs with high transparency, the selection of ILs and polymer monomers is particularly important. Here, we compare the compatibility of the three ILs with different polymers. The polymer monomers consist of acrylic acid, 2-diethylaminoethyl methacrylate, and six types of olefin monomers (Table S1).

The conductivity, thermal stability, and optical properties of GPEs were obviously improved by introducing an 3D ionically cross-linked network trapped IL-1-ethyl-3methylimidazolium bis(trifluoromethylsulfonyl)imide ([Emim]TFSI) and a highly conductive Li+ source LiTFIS into GPE (GPE-ILs). Switching speed, optical modulations, and cycling stability of ECDs adopting this GPE-ILs were investigated afterwards.

\section{Materials and Methods}

\subsection{Materials}

Methyl methacrylate (MMA, anhydrous, 99\%), acrylic acid (AA, purity > 99\%), 2diethylaminoethyl methacrylate (DEA, 99\%), ethyl alcohol (anhydrous, 99.7\%), and tungsten chloride $\left(\mathrm{WCl}_{6}, 99.5 \%\right)$ were purchased from Aladdin (Shanghai, China). Moreover, 1ethyl-3-methylimidazoliumbis[(trifluoromethyl)sulfonyl]imide([Emim]TFSI, purity $>99 \%)$ and lithium bis(trifluoromethylsulfonyl)imide (LiTFSI, anhydrous, 99\%) were purchased from MonILs Chemical (Shanghai) Co. Ltd., China. Dibenzoyl peroxide (BPO, AR) was provided by Sigma-Aldrich. Platinum electrodes (DJS-1C) were obtained from Shanghai Leici. The FTO-coated glass sheet (sheet resistance: $5-7 \Omega \mathrm{sq}^{-1}$ ) was obtained from Zhuhai Kaivo Optoelectronic Technology Co., Ltd. (Zhuhai, China).

\subsection{Preparation of the GPE-ILs}

Ionically cross-linked gel networks were formed by copolymerization of MMA, DEA, and AA. The synthesis was completed via following steps: $1.1 \mathrm{~mL}$ DEA and $1 \mathrm{~mL}$ AA were added into $8 \mathrm{~mL}$ MMA solution in order to form a mixture of MDA. 2. Ionic liquid [Emim]TFSI and MDA were mixed uniformly with a volume ratio of 2:1. 3. Then, $10 \mathrm{mg}$ $\mathrm{BPO}$, serving as an initiator, and a certain amount of LiTFSI was added to the [Emim]TFSI and MDA mixture. 4 . This mixture were ultrasonicated for $1.5 \mathrm{~h}$ until the mixture changes to a clear and transparent solution. 5. The solution was bubbled with nitrogen for $30 \mathrm{~min}$ to ensure an $\mathrm{O}_{2}$-free environment, and then, the remaining gas dissolved in the system was exhausted. 6. This $\mathrm{O}_{2}$-free solution was transferred to a sealed mold composed of two pieces of FTO glass. 7. This mold was then heat treated at $80^{\circ} \mathrm{C}$ for $12 \mathrm{~h}$ (Figure 1a). The major reaction can be illustrated as two steps: protonation process of DEA and AA and the process of free radical bulk polymerization (Figure 1b). Finally, a free-standing GPE-ILs film was obtained. 
(a)

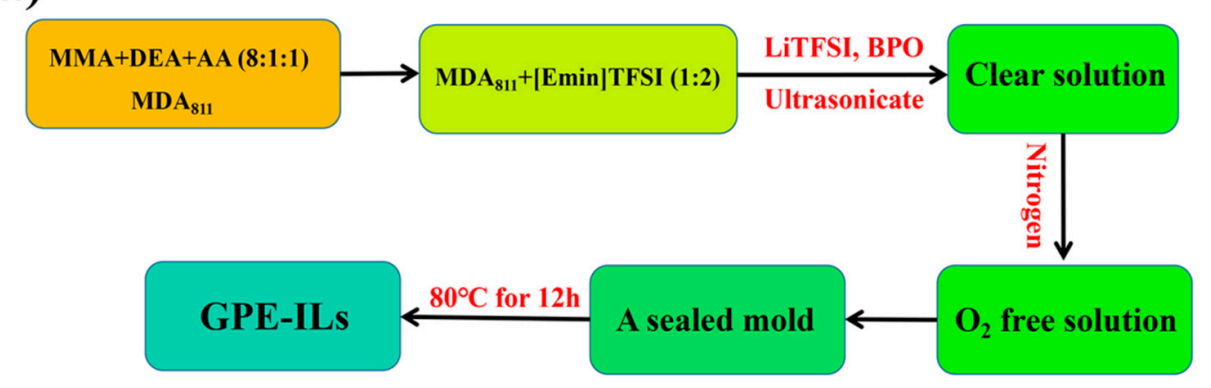

(b)

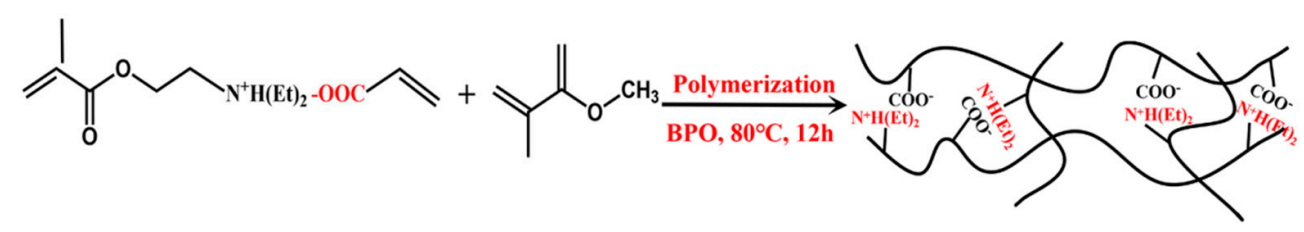

Figure 1. $(\mathbf{a}, \mathbf{b})$ Synthesis process of an ionic liquid-based ionically cross-linked gel polymer electrolyte (GPE-ILs).

\subsection{Fabrication of the Electrochromic Layers}

$\mathrm{WO}_{3}$ films were deposited on FTO glasses through a templated sol-gel process in an ultrasonic sprayer (Sono-Tek, Corporation, Milton, NY, USA), which was reported previously [39].

\subsection{Assembly of EC Device}

ECDs with a sandwich structure of glass/FTO/ $\mathrm{WO}_{3} / \mathrm{GPEs}$-ILs/FTO/glass were assembled by adding GPE-ILs in between a $\mathrm{WO}_{3}$-coated FTO glass and a bare FTO glass, which is as shown in Figure 2.

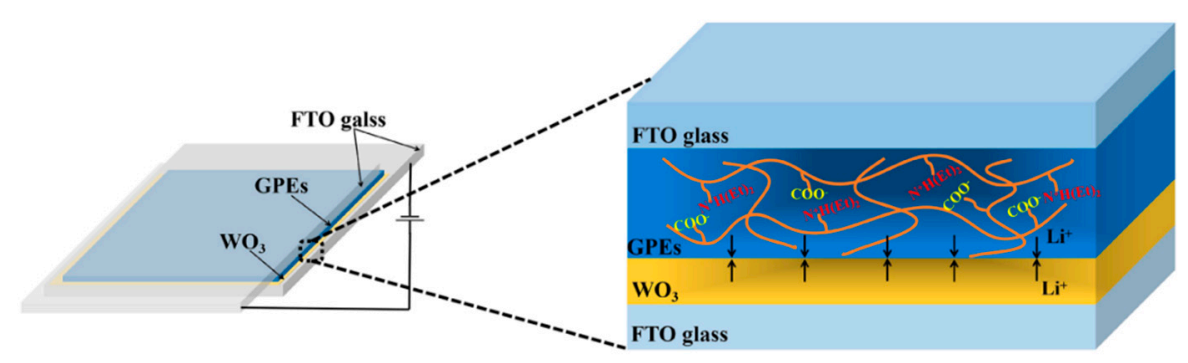

Figure 2. The assembly process of the electrochromic device (ECD).

\subsection{Characterization}

\subsubsection{The Thermal Properties of GPE-ILs}

Thermogravimetric analysis (TGA) of GPE-ILs was performed with a Netzsch Instruments simultaneous thermal analyzer (STA449F3) from 25 to $600{ }^{\circ} \mathrm{C}$ with a heating rate of $10^{\circ} \mathrm{C} \mathrm{min}^{-1}$ under nitrogen atmosphere. The differential scanning calorimetry (DSC) of the samples was carried out using a TA-DSC2500 instrument with a temperature ranging from -80 to $150{ }^{\circ} \mathrm{C}$ and heating/cooling rate of $10^{\circ} \mathrm{C} \mathrm{min}-1$. Tensile stress strain curve of GPE-ILs was obtained using an Electronic Universal Material Testing Machine (Instron 5967). The length and diameter of the samples were 40 and $4 \mathrm{~mm}$, respectively, and the stretching rate was $10 \mathrm{~mm} \mathrm{~min}{ }^{-1}$.

\subsubsection{The Electrochemical Performance of GPE-ILs}

The ionic conductivity of the GPE-ILs from $-10{ }^{\circ} \mathrm{C}$ to $80{ }^{\circ} \mathrm{C}$ were measured by alternating current impedance spectroscopy, which was obtained form an electrochemical 
workstation (Bio-Logic SP-300) under working conditions of a test frequency range from $0.1 \mathrm{~Hz}$ to $1 \mathrm{MHz}$ with the amplitude of $10 \mathrm{mV}$. The platinum electrodes (DJS-1C) are placed in the unpolymerized precursor solution. After the polymerization is completed, the GPEILs can fully contact the electrode, which obviously reduces the test error caused by the poor contact between the gel and the electrode. The electrochemical stability window (ESW) of GPE-ILs was measured by linear sweep voltammetry with a scan rate of $10 \mathrm{mV} \mathrm{s}^{-1}$ and a voltage range from 0 to $5 \mathrm{~V}$. The GPE-ILs was sandwiched between two sheets of FTO glass, which acted as the reference and working electrode, respectively.

\subsubsection{The Optical Transmittances of the ECDs}

Optical transmittances of the ECDs were measured using an ultraviolet visible nearinfrared spectrophotometer (Lambda 750S, PerkinElmer) with wavelength ranging from 350 to $800 \mathrm{~nm}$. Electrochemical workstation (Bio-Logic SP-300) was used to measure chronoamperometry (CA) of the ECDs and the applied voltage was stepped between -3.0 and $+3.0 \mathrm{~V}$ with step intervals of $40 \mathrm{~s}$.

\section{Results and Discussion}

\subsection{The Thermal Properties of GPE-ILS}

Figure 3a shows DSC thermograms for GPE-ILs over the temperature range from -100 to $150^{\circ} \mathrm{C}$. As shown in the enlarged view of area for glass transition Figure $3 \mathrm{~b}$, the starting point temperature of the glass transition is $-55.6^{\circ} \mathrm{C}$, and the ending point temperature is $-51.2{ }^{\circ} \mathrm{C}$, so the glass transition temperature is $-53.4^{\circ} \mathrm{C}$, which is consistent with the above analysis results of GPE-ILs that have no phase transition at $-10^{\circ} \mathrm{C}$. When the temperature is higher than glass transition temperature, lithium ions can easily and quickly migrate in the electrolyte, which results in high ionic conductivity [40]. Consequently, the conductivity of GPE-ILs at $-10^{\circ} \mathrm{C}$ still reaches $5.68 \times 10^{-4} \mathrm{~S} \mathrm{~cm}^{-1}$, and when the temperature is above the glass transition temperature of $-54.3^{\circ} \mathrm{C}$, the conductivity of GPE-ILs does not decrease sharply due to the phase transition. Therefore, ECDs with GPE-LIs as electrolyte can be used normally in a wide temperature range.

(a)

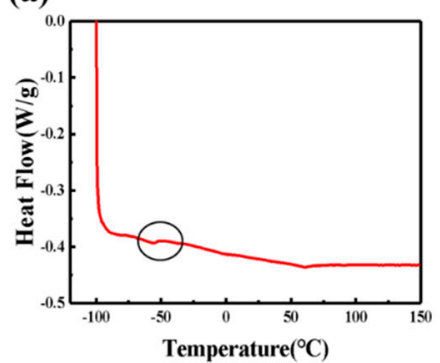

(c)

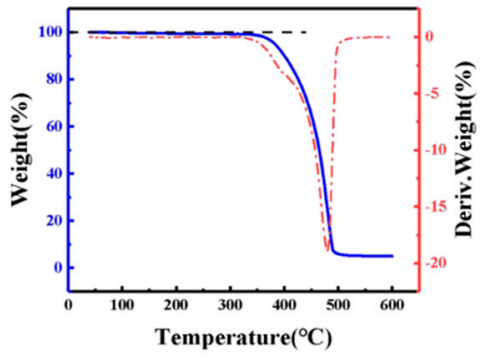

(b)

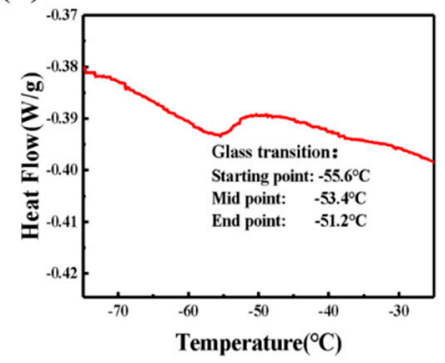

(d)

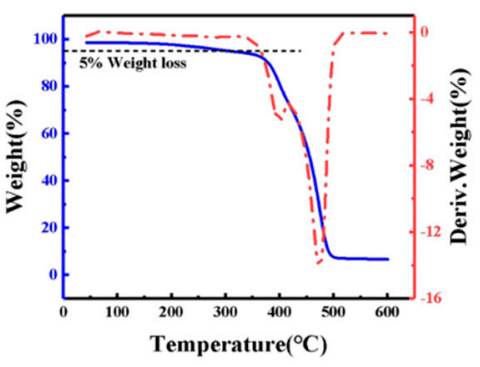

Figure 3. (a) Differential scanning calorimetry (DSC) thermograms for GPE-ILs over the temperature range from -100 to $150{ }^{\circ} \mathrm{C}$ at a heating rate of $10^{\circ} \mathrm{C} \mathrm{min}^{-1}$. (b) Enlarged view of area for glass transition. TGA and its DTG curve of (c) [Emim]TFSI and (d) GPE-ILs.

Weight loss of most organic gel polymer electrolytes at $300{ }^{\circ} \mathrm{C}$ is more than $15 \%$ [12,41-44] that can cause a serious long-term stability issues. Existence of carbonate-based plasticizers 
in electrolyte was considered as a major reason. Replacing solvents such as PE and EC with thermally stable [Emim]TFSI can improve thermal stabilities. Figure 3c,d shows the TGA and DTG curves of [Emin]TFSI and GPE-ILs; the TGA curves illustrates that [Emim]TFSI has almost no weight loss at $350{ }^{\circ} \mathrm{C}$. while GPE-ILs based on [Emim]TFSI has a weight loss of $5 \%$ at $300{ }^{\circ} \mathrm{C}$ probably arisen from volatilization of incompletely polymerized monomers. As being illustrated from TG results, the weight loss stage of GPE-ILs at $300-500{ }^{\circ} \mathrm{C}$ is separated into two stages: from 300 to $420{ }^{\circ} \mathrm{C}$ and from 400 to $500{ }^{\circ} \mathrm{C}$. At $300-420^{\circ} \mathrm{C}$, the weight loss rate of GPE-ILs is higher than [Emim]TFSI, which indicated that the polymer host of GPE-ILs is decomposed. At $420-600{ }^{\circ} \mathrm{C}$, the weight loss rate of GPE-ILs was basically equal to that of [Emim]TFSI, indicating that the weight loss within this temperature range was accounted for [Emim]TFSI [45]. In general, GPE-ILs based on [Emim]TFSI demonstrated a good thermal stability below $300^{\circ} \mathrm{C}$.

\subsection{The Ionic Conductivity of GPE-ILs}

Figure 4a shows the AC impedance spectrum of [Emim]TFSI and GPE-ILs at $25^{\circ} \mathrm{C}$, an equivalent circuit as shown in Figure $4 \mathrm{~b}$ is applied to fit experimental results. Therein, $R s$ represents the bulk resistance; $\mathrm{Rf}$ is the interfacial resistance; $\mathrm{CPE}$ is the constant phase element. In addition, then the bulk resistance values are fitted by Zview software. The ionic conductivity of the electrolytes was calculated according to Equation (1):

$$
\sigma=\frac{1}{R S} \frac{l}{S}
$$

where $\sigma$ is the conductivity, Rs is the bulk resistance, $l$ is the distance between two platinum electrodes, and $S$ is the interface area between the platinum electrode and the PADA gel electrolyte. In the present measurement, $l / S=2 \mathrm{~cm}^{-1}$.

(a)

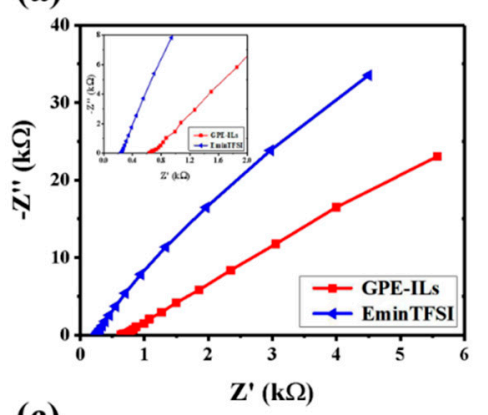

(c)

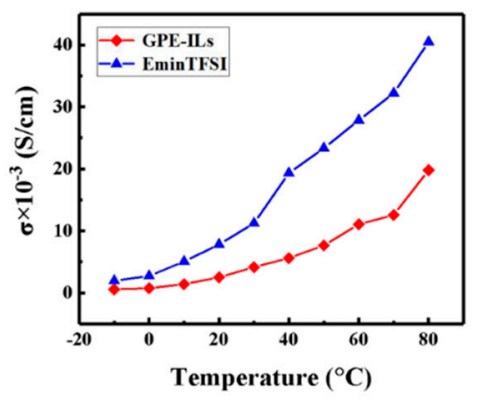

(b)

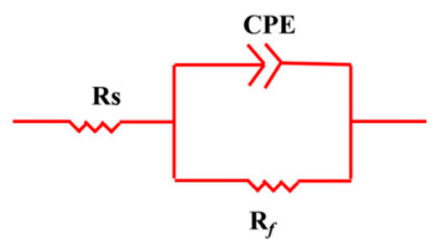

(d)

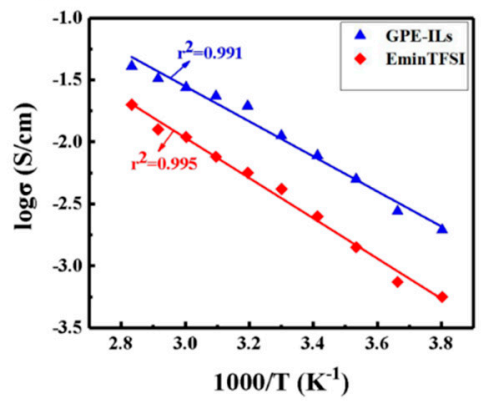

Figure 4. (a) Nyquist plots of different electrolytes at $25^{\circ} \mathrm{C}$. (b) The equivalent circuit for electrolytes in present work. (c) Ionic conductivity of GPE-ILs and the ionic liquid in the range from -10 to $80^{\circ} \mathrm{C}$. (d) Temperature dependence of the ionic conductivity of the GPE-ILs and the ionic liquid.

Figure $4 \mathrm{c}$ shows the ion conductivity of GPE-ILs and [Emim]TFIS from -10 to $80^{\circ} \mathrm{C}$. The ion conductivity of GPE-ILs is $3.29 \times 10^{-3} \mathrm{~S} \mathrm{~cm}^{-1}$ at $25^{\circ} \mathrm{C}$. In comparison, according to numerous reported studies, the GPEs with chemical cross-linked and organic solvents as liquid electrolyte exhibit relatively low ionic conductivities ranging from $10^{-5}$ to about 
$10^{-4} \mathrm{~S} \mathrm{~cm}^{-1}$ at $25^{\circ} \mathrm{C}$ (Table 1). Figure $4 \mathrm{~d}$ exhibits the temperature dependence of the ionic conductivity of the GPE-ILs and the ionic liquid. Generally, the relationship between the ionic conductivity of the liquid electrolyte and the temperature can be described by the Arrhenius equation (Equation (2))

$$
\sigma=A \exp \left(\frac{-E a}{K T}\right),
$$

where $\sigma$ is the ionic conductivity, $A$ is the pre-exponential factor, $E a$ is the activation energy, $K$ is the Boltzmann constant, and $T$ is the temperature in Kelvin.

Table 1. Switching times of several reported ECDs and the ionic conductivity of gel polymer electrolyte.

\begin{tabular}{|c|c|c|c|c|}
\hline ECDs Construction & $\begin{array}{l}\text { Ionic Conductivity } \\
\text { (S/cm) }\end{array}$ & Switching Time (s) tc/tb & $\begin{array}{l}\text { Coloration Efficiency } \\
\qquad\left(\mathrm{cm}^{2} \mathrm{C}^{-1}\right)\end{array}$ & Ref. \\
\hline $\begin{array}{c}\mathrm{FTO} / \mathrm{WO}_{3} / \text { protonic gelatin-based solid } \\
\text { electrolyte } / \mathrm{NiO} / \mathrm{FTO}\end{array}$ & $1.28 \times 10^{-5}\left(25^{\circ} \mathrm{C}\right)$ & $30 / 30$ & 38.1 & 12 \\
\hline $\mathrm{ITO} / \mathrm{WO}_{3} /$ PVB-based GPEFs $/ \mathrm{Ni}_{1-\mathrm{x}} \mathrm{O} / \mathrm{ITO}$ & $4.0 \times 10^{-5}\left(25^{\circ} \mathrm{C}\right)$ & $16.5 / 9.5$ & 175.3 & 20 \\
\hline $\begin{array}{c}\mathrm{FTO} / \mathrm{WO}_{3} / \mathrm{PMMA}^{-} \\
{[\mathrm{Emim}] \mathrm{BF}_{4} / \mathrm{LiClO}_{4} / \mathrm{FTO}}\end{array}$ & $2.9 \times 10^{-3}\left(25^{\circ} \mathrm{C}\right)$ & $62.6 / 41.2$ & 55.3 & 21 \\
\hline $\mathrm{FTO} / \mathrm{WO}_{3} / \mathrm{PADA}$ gel electrolyte/NiO/FTO & $1.33 \times 10^{-2}\left(25^{\circ} \mathrm{C}\right)$ & $7.5 / 8.5$ & 78.7 & 28 \\
\hline $\begin{array}{c}\mathrm{ITO} / \mathrm{WO}_{3} / \mathrm{d}- \\
\mathrm{PCL}(530) / \text { siloxane }_{2}[\mathrm{Emim}] \mathrm{BF}_{4} / \mathrm{LiCF}_{3} \mathrm{SO}_{3} / \mathrm{ITO}\end{array}$ & $4.0 \times 10^{-4}\left(36^{\circ} \mathrm{C}\right)$ & $30 / 50$ & 152 & 34 \\
\hline $\begin{array}{l}\text { ITO/PANI:DBSA/PVdFHFP-ICPTES-ZrO }{ }_{2} \\
\text { /PEDOT:PSS/ITO }\end{array}$ & $2.5 \times 10^{-4}\left(25^{\circ} \mathrm{C}\right)$ & $10.06 / 9.50$ & l & 46 \\
\hline $\mathrm{FTO} / \mathrm{WO}_{3} / \mathrm{GPE}-\mathrm{ILs} / \mathrm{FTO}$ & $3.29 \times 10^{-3}\left(25^{\circ} \mathrm{C}\right)$ & $7 / 4$ & 96.2 & This paper \\
\hline
\end{tabular}

As shown in Figure 4d, the $\log \sigma$ is linear with 1000/T for the GPE-ILs, and the linear correlation parameter $\mathrm{r}^{2}$ is 0.995 . Therefore, the ions transfer resistance of GPE-ILs is controlled by the thermal movement of ions so that the conductive behavior of GPE-ILs is similar to that of liquid electrolytes [27]. This structure enables the ionic liquid, as a continuous phase was encapsulated in the three-dimensional network of GPE-ILs, forming continuous transport channels to facilitate the diffusion and migration of ions [24]. In particular, at sub-zero temperature, the conductive behavior of GPE-ILs is still similar to that of ionic liquid, which proved that phase transition does not occur and its operability under a low temperature of $-10^{\circ} \mathrm{C}$.

\subsection{The Analysis of the ECD}

In our devices, the GPE-ILs as the ion transport layer actually also plays a role in ion storage, and the optical properties of ECDs can be changed because of the insertion/extraction processes of $\mathrm{Li}^{+}$and electrons in/out of the WO3 films. Figure 5a shows the bleaching and coloring state of ECD under a voltage bias of $\pm 3.0 \mathrm{~V}$. The ECD demonstrated a uniform blue color at colored state and transparency at bleached state. As shown in Figure $5 b$, the transmittance of the ECD in the bleaching and coloring state are $78.6 \%$ and $28.8 \%$, respectively. Transmittance variation of the ECD is $49.9 \%$ at $650 \mathrm{~nm}$. The transmittance of the ECD at $650 \mathrm{~nm}$ is measured in situ with a periodic voltage (depicted in Figure $5 c$ ). As shown in Figure $5 c$, the coloration time (tc) and bleaching time (tb) of ECD are 7 and $4 \mathrm{~s}$, respectively. The switching times are shorter than the previously reported publications (Table 1) due to the high ionic conductivity of GPE-ILs. 
(a)

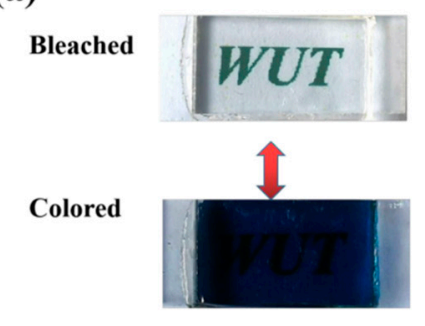

(c)

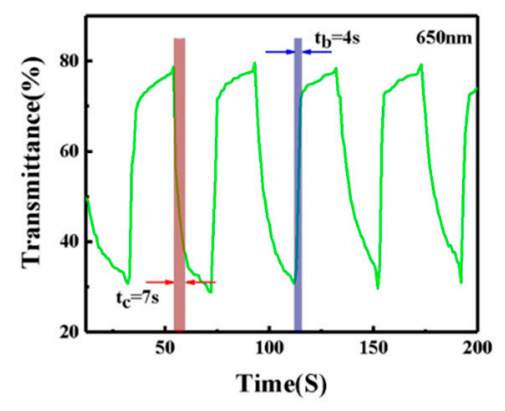

(b)
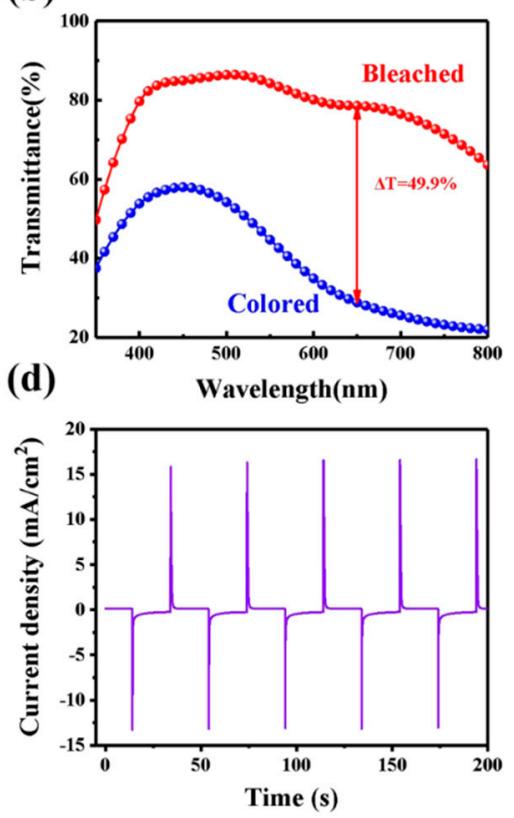

Figure 5. (a) Photographs of ECD in bleached and colored states. (b) Transmittance spectra of ECD with GPE-ILs in bleached and colored states from 350 to $800 \mathrm{~nm}$. (c) Switching speed of the ECD with GPE-ILs. (d) Chronoamperometry curve during the switching test. Potential: $\pm 3.0 \mathrm{~V}$, cycling time: $40 \mathrm{~s}$.

\subsection{The Coloration Efficiency and Cycling Durability of ECD}

Coloration efficiency $(C E)$ an important performance of ECDs is defined as the optical change caused by a unit charge density at a given wavelength, which could be determined by Equation (3):

$$
C E=\frac{\Delta O D}{\Delta Q}=\frac{\log (T b / T c)}{\Delta Q},
$$

where $\triangle O D$ represents the change of optical density. $T b$ and $T c$ are the transmittance at the bleached and colored states, respectively, and $\Delta Q$ can be calculated by the current integration (in Figure 5d). The $C E$ value of ECD is $96.2 \mathrm{~cm}^{2} \mathrm{C}^{-1}$, which is higher than some reported works (Table 1). The results show that ECDs based on GPE-ILs can obtain large optical modulation under low energy input, which is of great significance for energy saving.

A wide electrochemical window of electrolyte will ensure that ECDs can operate stably within the working voltage. Figure 6 a shows the result of a linear sweep voltammetry on GPE-ILs and the electrochemical stability window of GPE-ILs is $3.75 \mathrm{~V}$, which indicates that GPE-ILs is stable enough under the normal working voltage (3 V) of ECD. Figure $6 \mathrm{~b}$ shows the repeated coloring and bleaching process of GPE-ILs-based ECD during 50 cycles. The detail of transmittance for 200 cycles can be obtained in Figure S1. At the beginning, the transmittances of bleached and colored ECD are $77.6 \%$ and $27.7 \%$, respectively. Tb slightly drops and $T c$ rises after 100 cycles, $T b$ drops to $74.4 \%$, $T c$ rises slightly to $32.3 \%$, and the difference reduces to $42.1 \%$, which represents only a $7.8 \%$ decrease. As the cycle number increases to 200, the optical modulation of ECD can be still maintained to $35 \%$. As the cycle number increases, $T b$ gradually decreases, while $T c$ gradually increases, which is due to the ion trapping in tungsten oxide. 
(a)

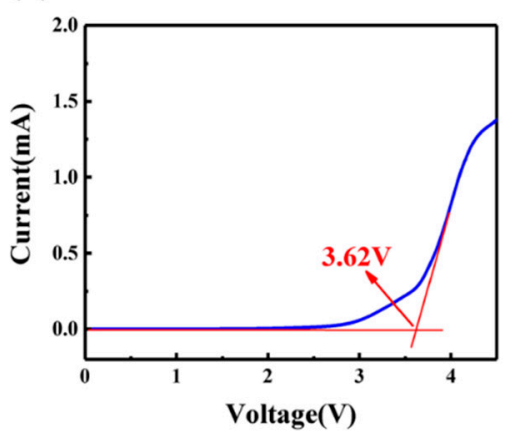

(b)

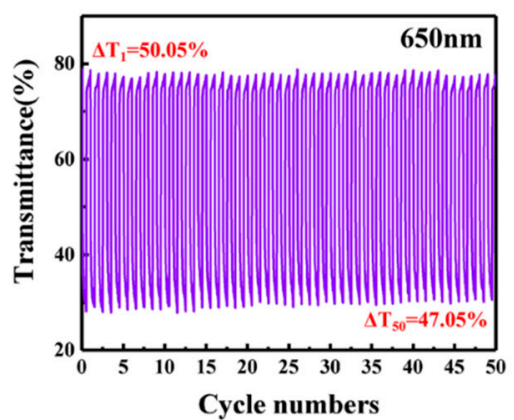

Figure 6. (a) Linear sweep voltammetry curve for GPE-ILs. (b) Transmittance of ECD with GPE-ILs at $650 \mathrm{~nm}$ for 50 cycles.

\subsection{The Self-Healing Ability of GPE-ILs}

GPE-ILs with good mechanical properties can further improve stability of ECDs. Figure $7 \mathrm{~b}$ shows in the tensile state and stress-strain curve of GPE-ILs that the breaking elongation of GPE-ILs is $400 \%$ and the breaking strength is $45 \mathrm{KPa}$. In Figure $7 \mathrm{c}$, the GPE-ILs is cut into two parts, and the new section is put together at room temperature (without adding any chemicals) for $12 \mathrm{~h}$. As shown in Figure $7 \mathrm{~d}$, the elongation at break of GPE-ILs after self-healing is 340\%, and the breaking strength is $35 \mathrm{KPa}$ indicating that the healing GPE-ILs can still maintain a good elongation and a certain strength. There are two main reasons for the self-healing of GPE-ILs. The first reason is when the ionically cross-linked polymer network is cut and placed together again, the network reconnects to form ionic bonds due to electrostatic attraction. On the other hand, the ionic liquid in GPE-ILs promotes the movement of polymer chains, and with the rearrangement of polymer chains, it is more conducive to the interaction of electrostatic attraction in the damaged area [22].

(a)

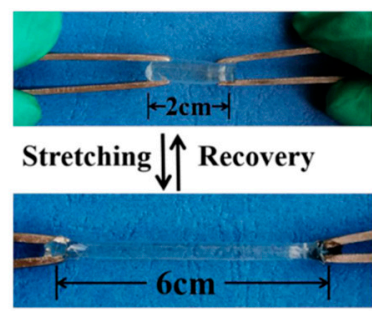

(c)

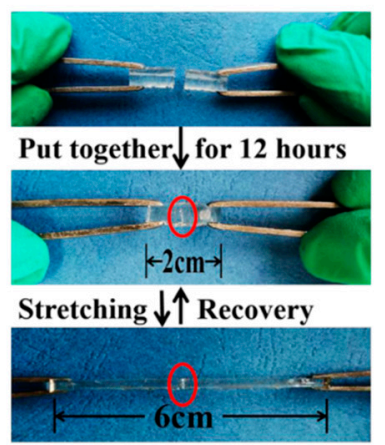

(b)

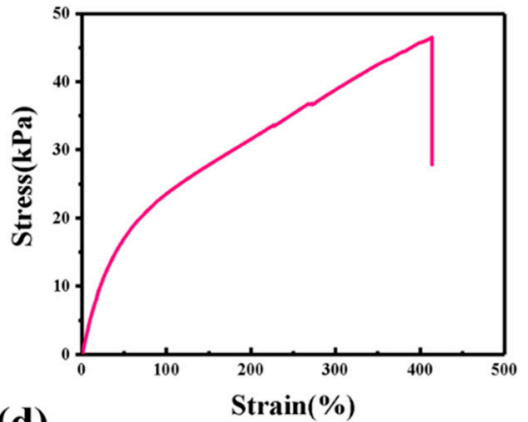

(d)

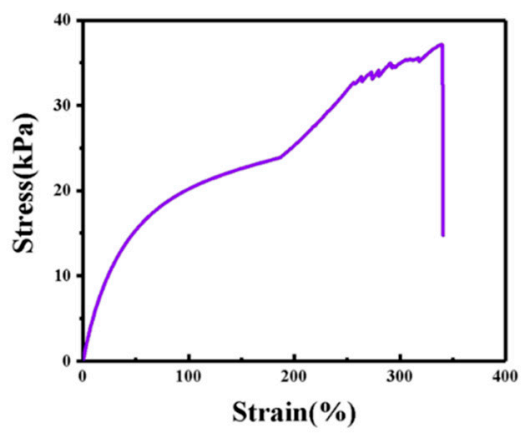

Figure 7. (a) Photographs demonstrating stretching of GPE-ILs. (b) Tensile stress strain of GPE-ILs. (c) Photographs demonstrating self-healing and stretching of GPE-ILs. (d) Tensile stress strain of self-healing GPE-ILs. 


\section{Conclusions}

A self-healing GPE-ILs was successfully fabricated, and ECDs adopting GPE-ILs as electrolyte demonstrated desirable properties of both operating and stabilities. The prepared ECD exhibits a large optical modulation of $49.9 \%$ at $650 \mathrm{~nm}$, short response time during the colored $(7 \mathrm{~s})$ and bleached $(4 \mathrm{~s})$ processes, high coloration efficiency of $96.2 \mathrm{~cm}^{2} \mathrm{C}^{-1}$, and good cycling performance of more than 200 cycles. These properties improvement can be attributed to the excellent properties of GPE-ILs. The ionic conductivities of GPE-ILs are $3.29 \times 10^{-3}$ and $0.58 \times 10^{-3} \mathrm{~S} \mathrm{~cm}^{-1}$ at $25^{\circ} \mathrm{C}$ and $-10^{\circ} \mathrm{C}$, respectively. The weight loss of GPE-ILs is only approximate $5 \%$ under $300^{\circ} \mathrm{C}$, and the glass transition temperature is $-53.4{ }^{\circ} \mathrm{C}$. In addition, GPE-ILs has superior self-healing ability that the tensile properties of GPE-ILs after self-healing can still maintain more than $80 \%$. In general, GPE-ILs not only have great potential in traditional electrochromic devices but also are expected to be applied to some new electronic devices such as foldable smart windows and stretchable electronic skins.

Supplementary Materials: The following are available online at https://www.mdpi.com/2073-4 360/13/5/742/s1, Figure S1: In situ optical response of PECD measured at $650 \mathrm{~nm}$. (a) 1-100th cycles. (b) 100-200th cycles. Potential: $3.0 \mathrm{~V}$, cycling time: 40 s, Table S1: Transparency of different components of ionically cross-linked gel polymer electrolytes (GPEs), Video S1: Electrochromic devices (ECD) in coloring and bleaching processes and the stretching of an ionic liquid-based ionically cross-linked gel polymer electrolyte (GPE-ILs).

Author Contributions: Conceptualization, W.C. and Y.P.; methodology, S.L.; validation, S.L., G.Z., and L.G.; investigation, M.C., T.X., and H.Z.; writing-original draft preparation, W.C. and S.L.; writing - review and editing, Y.P.; supervision, L.W. All authors have read and agreed to the published version of the manuscript.

Funding: This research received no external funding.

Institutional Review Board Statement: Not applicable.

Informed Consent Statement: Not applicable.

Data Availability Statement: The data presented in this study are available on request from the corresponding author.

Acknowledgments: This work was supported by the Technological Innovation Key project of Guangdong Province (skjtdzxrwqd2018005).

Conflicts of Interest: The authors declare no conflict of interest.

\section{References}

1. Yu, H.T.; Shao, S.; Yan, l.j.; Meng, H.; He, y.w.; Yao, C.; Xu, P.P.; Zhang, X.T.; Hu, W.P.; Huang, W. Highly robust and flexible $\mathrm{WO}_{3} \cdot 2 \mathrm{H}_{2} \mathrm{O} /$ PEDOT films for improved electrochromic performance in near-infrared region. J. Mater. Chem. C 2016, 4, 2269-2273. [CrossRef]

2. Shah, K.W.; Wang, S.X.; Soo, D.X.Y.; Xu, J.W. Viologen-Based Electrochromic Materials: From Small Molecules, Polymers and Composites to Their Applications. Polymers 2019, 11, 1839. [CrossRef] [PubMed]

3. Fan, H.W.; Li, K.R.; Liu, X.L.; Xu, K.X.; Su, Y.; Hou, C.Y.; Zhang, Q.H.; Li, Y.G.; Wang, H.Z. Continuously Processed, Long Electrochromic Fibers with Multi-Environmental Stability. ACS Appl. Mater. Interfaces 2020, 12, 28451-28462. [CrossRef]

4. Liang, H.; Li, R.; Li, C.; Hou, C.Y.; Li, Y.G.; Zhang, Q.H.; Wang, H.Z. Regulation of carbon content in MOF-derived hierarchicalporous NiO@C films for high-performance electrochromism. Mater. Horiz. 2019, 6, 571-579. [CrossRef]

5. Wang, H.F.; Barrett, M.; Duane, B.; Gu, J.; Zenhausern, F. Materials and processing of polymer-based electrochromic devices. Mater. Sci. Eng. B-Solid State Mater. Adv. Technol. 2018, 288, 167-174. [CrossRef]

6. Patel, K.J.; Bhatt, G.G.; Ray, J.R.; Suryavanshi, P.; Panchal, C.J. All-inorganic solid-state electrochromic devices: A review. J. Solid State Electrochem. 2010, 21, 337-347. [CrossRef]

7. Thakur, V.K.; Ding, G.Q.; Ma, J.; Lee, P.S.; Lu, X.H. Hybrid Materials and Polymer Electrolytes for Electrochromic Device Applications. Adv. Mater. 2012, 24, 4071-4096. [CrossRef]

8. Coskun, Y.; Cirpan, A.; Toppare, L. Construction of electrochromic devices using thiophene based conducting polymers. J. Mater. Sci. 2007, 42, 368-372. [CrossRef]

9. Li, X.F.; Perera, K.; He, J.Z.; Gumyusenge, A.; Mei, J.G. Solution-processable electrochromic materials and devices: Roadblocks and strategies towards large-scale applications. J. Mater. Chem. C 2019, 7, 12761-12789. [CrossRef] 
10. Eh, A.L.S.; Tan, A.W.M.; Cheng, X.; Magdassi, S.; Lee, P.S. Recent Advances in Flexible Electrochromic Devices: Prerequisites, Challenges, and Prospects. Energy Technol. 2018, 6, 33-45. [CrossRef]

11. Mortimer, R.J. Electrochromic Materials. Annu. Rev. Mater. Sci. 2011, 41, 241-268. [CrossRef]

12. Ramadan, R.; Elshorbagy, M.H.; Kamal, H.; Hashem, H.M.; Abdelhady, K. Preparation and characterization of protonic solid electrolyte applied to a smart window device with high optical modulation. Optik 2017, 135, 85-97. [CrossRef]

13. Huang, B.Y.; Zhang, Y.D.; Que, M.M.; Xiao, Y.B.; Jiang, Y.Q.; Yuan, K.; Chen, Y.W. A facile in situ approach to ion gel based polymer electrolytes for flexible lithium batteries. Rsc Adv. 2017, 7, 54391-54398. [CrossRef]

14. Ileperuma, O.A. Gel polymer electrolytes for dye sensitised solar cells: A review. Mater. Technol. 2013, 28, 65-70. [CrossRef]

15. Kang, S.S.; Fan, S.C.; Liu, Y.; Wei, Y.C.; Li, Y.; Fang, J.G.; Meng, C.Z. Al-ion polymer solid electrolyte. Acta Chim. Sin. 2019, 77, 647-652. [CrossRef]

16. Pawlicka, A.; Dragunski, D.C.; Guimaraes, K.V.; Avellaneda, C.O. Electrochromic devices with solid electrolytes based on natural polymers. Mol. Cryst. Liq. Cryst. 2004, 216, 105-112. [CrossRef]

17. Eren, E.; Aydin, M.F.; Oksuz, A.U. A practical approach for generation of WO3-based flexible electrochromic devices. J. Solid State Electrochem. 2020, 24, 1057-1065. [CrossRef]

18. Yun, T.Y.; Li, X.L.; Bae, J.; Kim, S.H.; Moon, H.C. Non-volatile, Li-doped ion gel electrolytes for flexible WO3-based electrochromic devices. Mater. Des. 2019, 162, 45-51. [CrossRef]

19. Kelly, F.M.; Meunier, L.; Cochrane, C.; Koncar, V. Evaluation of Solid or Liquid Phase Conducting Polymers Within a Flexible Textile Electrochromic Device. J. Disp. Technol. 2013, 9, 626-631. [CrossRef]

20. Zhang, F.; Dong, G.B.; Liu, J.; Ye, S.B.; Diao, X.G. Polyvinyl butyral-based gel polymer electrolyte films for solid-state laminated electrochromic devices. Ionics 2017, 23, 1879-1888. [CrossRef]

21. Tang, Q.F.; Li, H.Z.; Yue, Y.F.; Zhang, Q.H.; Wang, H.Z.; Li, Y.G.; Chen, P. 1-Ethyl-3-methylimidazolium tetrafluoroborate-doped high ionic conductivity gel electrolytes with reduced anodic reaction potentials for electrochromic devices. Mater. Des. 2017, 118, 279-285. [CrossRef]

22. Zhang, W.R.; Jiang, H.Y.; Chang, Z.G.; Wu, W.; Wu, G.H.; Wu, R.M.; Li, J.Q. Recent achievements in self-healing materials based on ionic liquids: A review. J. Mater. Sci. 2020, 55, 13543-13558. [CrossRef]

23. Cao, Y.; Morrissey, T.G.; Acome, E.; Allec, S.I.; Wong, B.M.; Keplinger, C.; Wang, C. A Transparent, Self-Healing, Highly Stretchable Ionic Conductor. Adv. Mater. 2017, 29, 1605099. [CrossRef] [PubMed]

24. Das, S.; Martin, P.; Vasilyev, G.; Nandi, R.; Amdursky, N.; Zussman, E. Processable, Ion-Conducting Hydrogel for Flexible Electronic Devices with Self-Healing Capability. Macromolecules 2020, 53, 11130-11141. [CrossRef]

25. Hou, C.Y.; Duan, Y.R.; Zhang, Q.H.; Wang, H.Z.; Li, Y.G. Bio-applicable and electroactive near-infrared laser-triggered self-healing hydrogels based on graphene networks. J. Mater. Chem. 2012, 22, 14991-14996. [CrossRef]

26. Taylor, D.L.; Panhuis, M.I.H. Self-Healing Hydrogels. Adv. Mater. 2016, 28, 9060-9093. [CrossRef]

27. Chen, W.Y.; Ou, Z.W.; Tang, H.T.; Wang, H.; Yang, Y.J. Study of the formation of a solid electrolyte interphase (SEI) in ionically crosslinked polyampholytic gel electrolytes. Electrochim. Acta 2008, 53, 4414-4419. [CrossRef]

28. Chen, W.Y.; Zhu, C.Z.; Guo, L.; Yan, M.Y.; Wu, L.L.; Zhu, B.; Qi, C.J.; Liu, S.Y.; Zhang, H.; Peng, Y. A novel ionically crosslinked gel polymer electrolyte as an ion transport layer for high-performance electrochromic devices. J. Mater. Chem. C 2019, 7, 3744-3750. [CrossRef]

29. Shi, M.N.; Lin, T.R.; Wang, Y.; Hu, Y.; Peng, J.; Li, J.Q.; Zhai, M.L. One-step radiation synthesis of novel star-shaped polymeric ionic liquid-POSS gel electrolytes with high ionic conductivity and mechanical properties for supercapacitor. J. Mater. Sci. 2020, 55, 16347-16359. [CrossRef]

30. Moon, H.C.; Lodge, T.P.; Frisbie, C.D. DC-Driven, Sub-2 V Solid-State Electrochemiluminescent Devices by Incorporating Redox Coreactants into Emissive Ion Gels. Chem. Mater. 2014, 26, 5358-5364. [CrossRef]

31. Castner, E.W.; Wishart, J.F. Spotlight on ionic liquids. J. Chem. Phys. 2010, 132, 120901. [CrossRef]

32. Liu, H.; Yu, H.J. Ionic liquids for electrochemical energy storage devices applications. J. Mater. Sci. Technol. 2019, 35, 674-686. [CrossRef]

33. Goncalves, M.C.; Pereira, R.F.P.; Alves, R.; Nunes, S.C.; Fernandes, M.; Goncalves, H.M.R.; Pereira, S.; Silva, M.M.; Fortunato, E.; Rego, R.; et al. Electrochromic Device Composed of a Di-Urethanesil Electrolyte Incorporating Lithium Triflate and 1-Butyl-3Methylimidazolium Chloride. Front. Mater. 2020, 7, 139. [CrossRef]

34. Fernandes, M.; Leones, R.; Costa, A.M.S.; Silva, M.M.; Pereira, S.; Mano, J.F.; Fortunato, E.; Rego, R.; de Zea Bermudez, V. Electrochromic devices incorporating biohybrid electrolytes doped with a lithium salt, an ionic liquid or a mixture of both. Electrochim. Acta 2015, 161, 226-235. [CrossRef]

35. Sun, S.J.; Song, J.; Feng, R.X.; Shan, Z.Q. Ionic liquid gel electrolytes for quasi-solid-state dye-sensitized solar cells. Electrochim. Acta 2012, 69, 51-55. [CrossRef]

36. Kaur, D.P.; Yamada, K.; Park, J.S.; Sekhon, S.S. Correlation between Ion Diffusional Motion and Ionic Conductivity for Different Electrolytes Based on Ionic Liquid. J. Phys. Chem. B 2005, 113, 5381-53390. [CrossRef]

37. Egashira, M.; Yoshimoto, N.; Morita, M. The Addition of Ethylene Carbonate to Ionic Liquid Gel Electrolyte for Lithium Batteries. Electrochemistry 2009, 77, 652-655. [CrossRef]

38. Wu, J.H.; Lan, Z.; Lin, J.M.; Huang, M.L.; Huang, Y.F.; Fan, L.Q.; Luo, G.G. Electrolytes in Dye-Sensitized Solar Cells. Chem. Rev. 2015, 115, 2136-2173. [CrossRef] [PubMed] 
39. Li, C.P.; Lin, F.; Richards, R.M.; Engtrakul, C.; Tencet, R.C.; Wolden, C.A. The influence of sol-gel processing on the electrochromic properties of mesoporous $\mathrm{WO}_{3}$ films produced by ultrasonic spray deposition. Sol. Energy Mater. Sol Cells 2014, 121, 163-170. [CrossRef]

40. Zhang, D.S.; Zhou, J.P.; Shen, F.L. A hybrid gel polymer electrolyte with imide groups modified by the coupling agent and its application in electrochromic devices. J. Sol.-Gel. Sci. Technol. 2020, 97, 393-403. [CrossRef]

41. Akashi, H.; Shibuya, M.; Orui, K.; Shibamoto, G.; Sekai, K. (Practical performances of Li-ion polymer batteries with $\mathrm{LiNi}_{0.8} \mathrm{Co}_{0.2} \mathrm{O}_{2}$, MCMB, and PAN-based gel electrolyte. J. Power Sources 2002, 112, 577-582. [CrossRef]

42. AFlora, X.H.; Ulaganathan, M.; Rajendran, S. Role of Different Plasticizers in Li-Ion Conducting Poly(Acrylonitrile)-Poly(Methyl Methacrylate) Hybrid Polymer Electrolyte. Int. J. Polym. Mater. Polym. Biomater. 2013, 62, 737-742.

43. Guan, H.Y.; Lian, F.; Wen, Y.; Pan, X.R.; Sun, J.L. Thermal Stability of Novel Polyvinyl Formal Based Gel Polymer Electrolyte. Chem. J. Chin. Univ. Chin. 2014, 35, 80-84.

44. Shin, H.; Nguyen, C.; Kim, B.; Han, M.; Kim, J.S.; Kim, J. Synthesis and characteristics of acrylol borate as new acrylic gelator for lithium secondary battery. Macromol. Res. 2008, 16, 134-138. [CrossRef]

45. Yao, M.H.; Li, Q.; Xia, Y.Q.; Liang, Y.M. Synthesis, Characterization, Thermal Analyses, and Spectroscopic Properties of Novel Naphthyl-Functionalized Imidazolium Ionic Liquids. Russ. J. Phys. Chem. A 2018, 92, 502-507. [CrossRef] 